\title{
The Improvement of the Wall Temperature Calculation Procedure for the Post-Crisis Region of the NPP Heated Channels
}

\author{
N. D. Agafonova ${ }^{1} \&$ I. L. Paramonova ${ }^{1}$ \\ ${ }^{1}$ Saint-Petersburg State Polytechnic University, St.Petersburg, Russia \\ Correspondence: N. D. Agafonova, St.Petersburg State Polytechnic University, St.Petersburg, 195251, Russia. \\ Tel: 7-812-552-6591. E-mail: a-n-d-2011@mail.ru
}

Received: October 10, 2014

Accepted: October 24, 2014 Online Published: November 14, 2014

doi:10.5539/mer.v4n2p60

URL: http://dx.doi.org/10.5539/mer.v4n2p60

\begin{abstract}
The reliable wall temperature prediction is important for the analysis of operation and safety of both nuclear reactors and direct-flow steam generators with high-temperature fluids. The onset of dangerous temperature excursion is possible in the post-crisis region of the heated channels when the inverted annular or the dispersed flow regime occurs. The wall temperature calculations for both flow regimes are represented. The data of Hammouda, Lapperiere, Chen, Miropolsky, Bennett and some other investigators were processed. The obtained average error and deviation are less than those which take place when special best estimate computer code KORSAR is used. Specified result was reached by the way of the engineering procedures correction and may be applied for the closure correlations improvement which is needed in two-fluid two-phase flow models. The conclusion is made that the correct choice of the integration step and the method of the critical quality determination produce effect on the adequate wall temperature prediction.
\end{abstract}

Keywords: dispersed flow regime, inverted annular flow regime, heated channel, nuclear reactor, post-crisis region, steam generator, wall temperature

\section{Introduction}

The thermal physical aspects are very important for the ground of the nuclear power systems under normal and emergency operation as well as the neutron-physical process study.

The reliable wall temperature prediction is urgent for the analysis of operation and safety of both nuclear reactors and direct-flow steam generators with high-temperature fluids. The onset of dangerous temperature excursion is possible in the post-crisis region of the heated channels when the inverted annular or the dispersed flow regime occurs.

The modern ideas about post-crisis heat transfer are based on the recognition of two fundamentally different mechanisms governing the onset of a situation in which a change occurs in the conditions of heat removal from a surface (the "poor" removal of heat by steam emerges instead of the "good" removal of heat by liquid, which leads to a growth of the wall temperature), namely, burnout and dryout. The burnout is connected with a transition from nucleate boiling of liquid to its less effective film boiling, and the dryout involves a disappearance of liquid film on a heating surface and transition from dispersed-annual to purely dispersed flow structure. In Russian scientific literature the post-dryout region is usually called a deteriorated heat transfer region and in foreign scientific literature - dispersed flow film boiling or DFFB.

It may be noticed that the level of the surface heat flux density at the burnout is much greater than at the dryout. The inverted annular flow regime is established at first in the post burnout region (also called inverted annual film boiling or IAFB) at the high wall heat flux density. It is characterized by a continuous liquid core separated from the wall by a vapor film. The wall temperature in the IAFB mode rapidly increases and becomes above Leidenfrost temperature. It is also known (Obot \& Ishii, 1988; Nakla, Groeneveld, \& Cheng, 2011) that the liquid core quickly collapses with the void fraction increase. The transition from the IAFB to DFFB mode takes place. This case differs from the post-dryout region in the level of wall temperature and, as effect, in the mechanism of the heat removal from the wall by drops: under direct contact of the drops with the surface for the relatively low temperatures or through the vapor layer for the high temperatures.

It is possible to indicate that the correct estimation of heat transfer at the inverted annular flow regime and at the dispersed flow regime, as well as determination of the IAFB zone existence are a key problems for the ground of 
nuclear power reactors working capacity and safety. The modern computer codes are used for thermal-hydraulic calculations of the nuclear equipment's work.

\section{Heat Transfer and the Wall Temperature Calculations in the Inverted Annular Flow Regime}

Since burnout is observed at high heat flux densities typical of the cores of water-cooled reactors, the increase of fuel rod cladding temperature may be very high, up to burn-through of the cladding. It should be noted that the bulk temperature of coolant flow may be well below the saturation temperature in this case.

The burnout conditions in the heat removal may occur in a nuclear reactor also at the surface heat loads lower than critical heat flux $q_{\text {cr }}$ when the faulty core is flooded with cold water. In this case, with comparatively low heat flux, when the wall temperature exceeds the minimal temperature at which the liquid wets the surface, the occurrence of inverted annual film boiling is being also possible.

The Hammouda model (Hammouda, Groeneveld, \& Cheng, 1997) is the only one being used when heat transfer under the conditions of inverted annular mode of two-phase flow can be described in a physically substantiated manner and at negative values of relative enthalpy $x_{e q}$ as well. This model is used in the latest versions of modern computer best estimate codes for in-circuit hydrodynamics and heat transfer, such as the KORSAR and TRAC codes. Some problems connected with the wall temperature calculation when using the Hammouda model are considered by Agafonova \& Paramonova (2013). It was shown that the temperature variation across the near-wall vapor layer and therefore the change in the physical properties of vapor may be considerable and produces an essential effect on the heat transfer and drag friction in vapor as compared with their values at constant physical properties of vapor (Petukhov, 1967; Kays \& Leunge, 1963). According to our calculations (Agafonova \& Paramonova, 2013) for the conditions of the experiments by Chen (2011) the wall temperature $\left(t_{w},{ }^{\circ} \mathrm{C}\right)$ was nearly two or three times as large as compared with the interfacial surface (or the liquid core surface) temperature which is equal to the saturation temperature $\left(t_{s},{ }^{\circ} \mathrm{C}\right)$. It is known (Petukhov, 1967; Kays \& Leunge, 1963) that for given situation:

$$
\frac{N u}{N u_{n c}}=\left(\frac{t_{w}}{t_{s}}\right)^{m}
$$

where $N u$ - the Nusselt number at the varying physical properties; $N u_{n c}-$ the Nusselt number at the constant physical properties.

In this connexion we offered the modification of the Hammouda's model by means of the temperature factor $\gamma_{I A F B}=t_{w} / t_{s}$ introduction (the temperature is expressed in Celsius degrees) and new approximations both for the influence coefficient $\theta$ in the range of Reynolds numbers $R e_{g}$ from 0 to $3 \times 10^{5}$ and for the vapor Nusselt number, which were obtained in this work. These approximations are required since in the original model (Hammouda et al., 1997) $R e_{g} \leq 9900$ and in practice $R e_{g}$ may be larger. All the necessary formulas in comparison with the original Hammouda model are provided in Table 1.

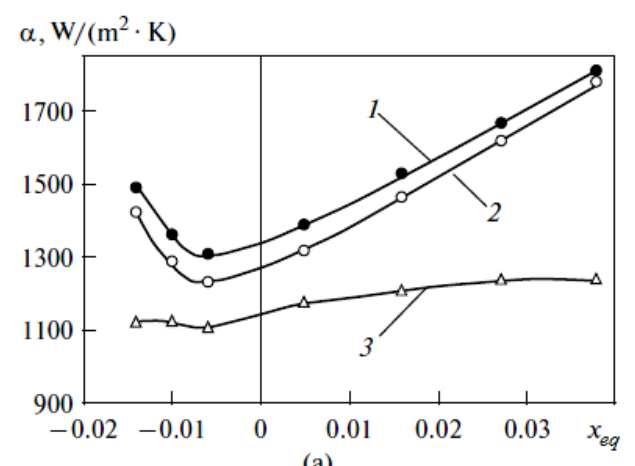

(a)

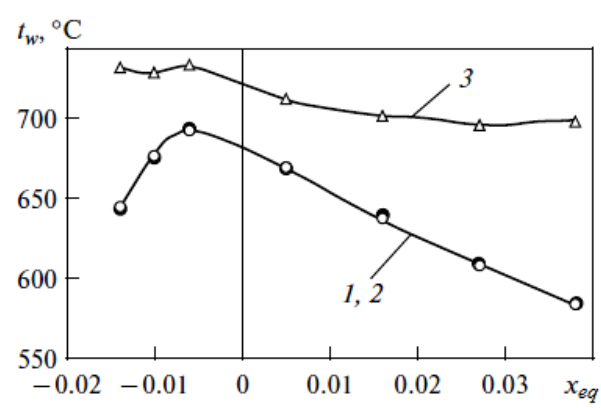

(b)

Figure 1. The dependences of the heat transfer coefficient (a) and the wall temperature (b) on the relative enthalpy (experimental data (Lapperiere \& Groeneveld, 1984) at $p=10 \mathrm{MPa}, \rho w=4406 \mathrm{~kg} /\left(\mathrm{m}^{2} \cdot \mathrm{s}\right)$, and $q_{w}=496 \mathrm{~kW} / \mathrm{m}^{2}$ :

1 - experimental data, 2 - calculated results of the present study, and 3 - results from calculations with using

Hammouda's original model (Hammouda et al., 1997)

Figure 1 shows a comparison between the calculated values of the heat transfer coefficient and the wall temperature with the experimental data obtained by (Lapperiere \& Groeneveld, 1984). Introduced corrections in the original Hammouda's model guarantee the best agreement of the mentioned values with the experimental data. 
In addition, the estimation of the channel length where the inverted annular flow regime with a smooth or wavy liquid core surface takes place was done according to the recommendations (Obot \& Ishii, 1988). This estimation showed that the region with the smooth and wavy liquid core surface may be equal to or less than $0.2 \mathrm{~m}$, but it is in this region that the heat transfer coefficient from the wall to vapor is minimum and the wall temperature is maximum The method under discussion of the wall temperature calculations is valid only in this relatively short region and the given fact has to be taken into account for the correct choice of the integration step to length when the computer codes for thermal-hydraulic prediction of the nuclear equipment's work are used.

Table 1. Calculation formulas for the heat transfer during film boiling determination (IAFB model)

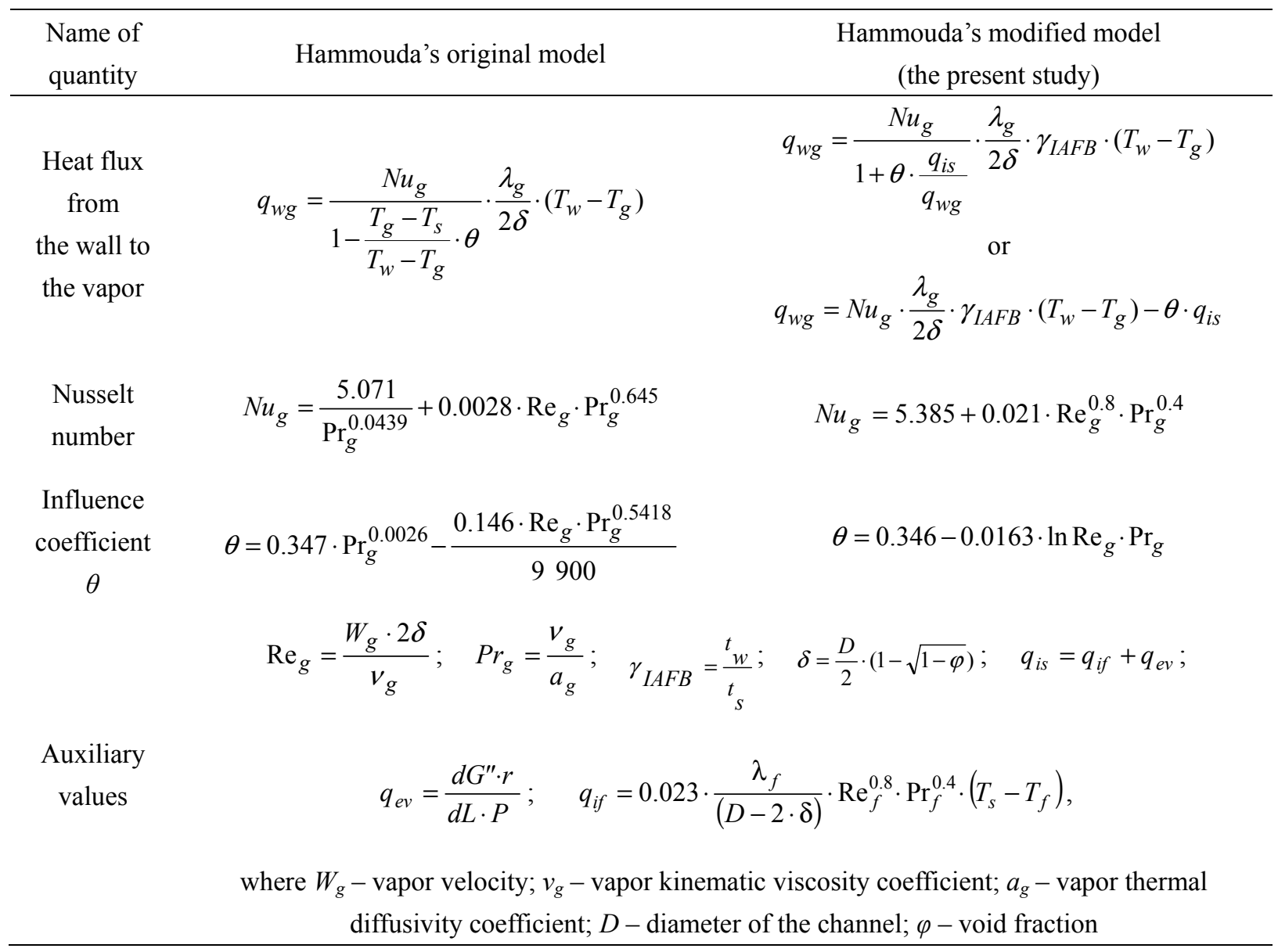

\section{Heat Transfer and the Wall Temperature Calculations in the Dispersed Flow Regime}

There is a wide choice of different techniques for the wall temperature estimation in the region of dispersed two-phase flow. It is quite clear that the noticeable diversity takes place when the calculated values of the wall temperature are compared with the experimental data especially at high values of the wall heat flux density $q_{w}$. Analysis carried out in the present work confirms this conclusion. The experimental data (Bennett, Hewitt, Kearsey \& Keeys, 1967) were processed with KORSAR code to obtain the wall temperature at DFFB mode (Figure 2).

In Figure 2 the length dependence of the wall temperature calculated by Mecholic (2011) with the modified program COBRA-TF is also represented. Both programs give the results fitted well into the experimental data in the dispersed-annular flow region and are not fit well for the dispersed flow. The difficulties of the dispersed flow mathematical modeling deal with the thermodynamic nonequilibrium and the deficiency of reliable recommendations for the droplets and wall interaction. 

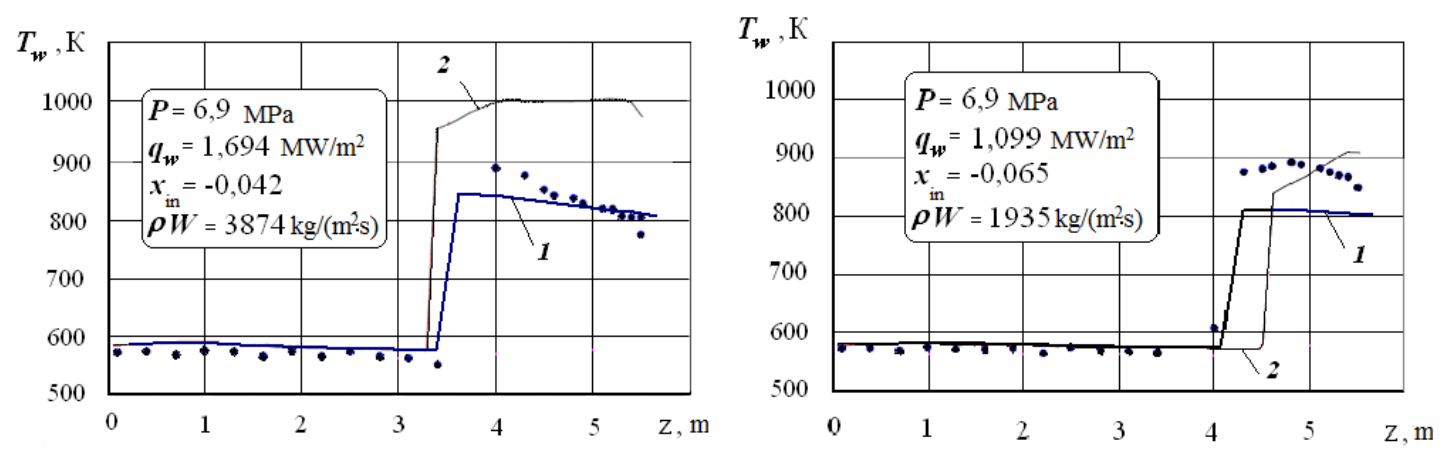

Figure 2. The comparison of the experimental wall temperatures (black points) (Bennett et al., 1967) and calculated values: 1 - with KORSAR code (the present work); 2 - with modified program COBRA-TF (Meholic, 2011)

The engineering (i.e. comparatively simple) model by Hein and Köhler (1986) seems to be the most correct among the nonequilibrium models for the dispersed flow film boiling. The main feature of this model is the determination of the vapor temperature (and then the wall temperature) in terms of the nonequilibrium factor $\omega=x_{a c t} / x_{e q}$. Hein and Köhler (1986) proposed the following equation for the determination of $\omega$ :

$$
\omega=\frac{2}{1+\sqrt{1+4 \frac{\bar{C}_{p g}}{r} \frac{q_{w}}{\left(\alpha_{g d} A_{d} / A_{w}\right)}}},
$$

where term $\alpha_{g d} A_{d} / A_{w}$, i.e. the product of the heat transfer coefficient $\alpha_{g d}$ between the vapor and the liquid droplets and the area $A_{d}$ of the evaporating droplets devided by area $A_{w}$ of the heated surface, is calculated with relationships derived by Hein and Köhler from the experimental data. All formulas needed for use of this model in practice are represented in Table 2. It has to be mentioned that the model by Hein and Köhler gives a rather reliable prediction of the maximum wall temperature values and is recommended to use in VDI Heat Atlas (2010).

The model (Hein \& Köhler, 1986) has some limitations to be directly used in the closing correlations system of the modern computer codes based on the two-liquid model of the two-phase flow. One of them is the determination of the effective heat transfer coefficient $\alpha_{w}^{H K}$ from the wall to the dispersed flow (without dividing in parts: to the vapor and to the liquid droplets). Another one - is the nonequilibrium factor constancy with the increase of the void fraction.

A modified version of Hein-Köhler's model for heat transfer in the dispersed flow mode region is proposed in the present study, central to which is the use of correction in calculating nonequilibrium factor of two-phase flow. The evaluation shows that in the dispersed flow (post-dryout region) the order of mean liquid droplet diameter magnitude is $10^{-6} \mathrm{~m}$ and the droplet velocity approximately is equal to the vapor velocity. Under these conditions the droplet breakup is absent and they evaporate without total amount change. This total amount is equal to the corresponding value at the point of dryout.

The correction $\gamma_{D F F B}$ takes into account the decrease of total droplet surface area under evaporation and may be defined as:

$$
\gamma_{D F F B}=2 \cdot\left(\frac{1-x_{a c t}}{1-x_{a c t}^{c r}}\right)^{2 / 3} .
$$

The wall temperature calculations with proposed correction in the relationship (2) for the nonequilibrium factor $\omega$ determination are represented in Figure 3. Experimental regime parameters are shown in Table 3. All the necessary formulas are provided in Table 2.

The relative error under comparison of calculated and experimental wall temperatures (the temperature is expressed in Celsius degrees) is less than $12 \%$. 
Table 2. Calculation formulas for determining heat transfer during the dispersed flow (DFFB model)

\begin{tabular}{|c|c|}
\hline Name of quantity & $\begin{array}{l}\text { Modified model by Hein-Köhler } \\
\text { (the present study) }\end{array}$ \\
\hline $\begin{array}{l}\text { Heat flux fromthe } \\
\text { wall to vapor }\end{array}$ & $q_{w g}=N u_{g} \cdot \frac{\lambda_{g}}{D} \cdot\left(T_{w}-T_{g}\right)$ \\
\hline $\begin{array}{l}\text { The superheated } \\
\text { vapor temperature }\end{array}$ & $T_{g}=T_{S}+\frac{r}{\bar{C}_{p g}}\left(\frac{1}{\omega}-1\right)$ \\
\hline & $2 \omega=\frac{2}{1+\sqrt{1+4 \frac{{ }^{C_{p g}}}{2}} q_{w}}$ \\
\hline $\begin{array}{l}\text { factor in dispersed } \\
\text { flow }\end{array}$ & 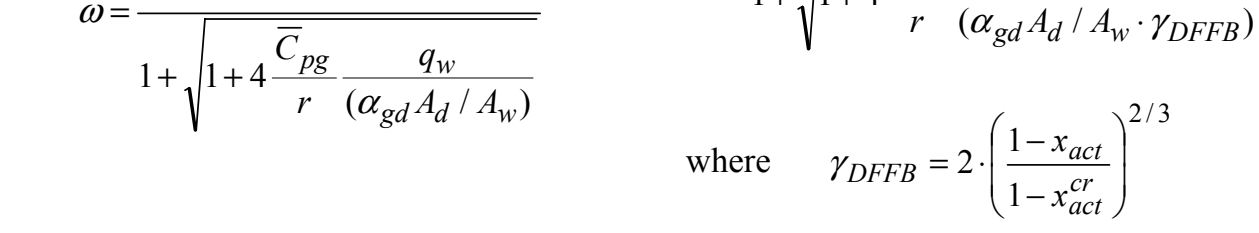 \\
\hline $\begin{array}{l}\text { The group of } \\
\text { parameters } \\
\alpha_{g d} A_{d} / A_{W}\end{array}$ & $\alpha_{g d} \frac{A_{d}}{A_{\mathrm{w}}}=\left\{\begin{array}{l}1.473 \cdot 10^{-7}\left(\frac{\rho W}{L}\right)^{1.33} ; \frac{\rho W}{L}<1767 \cdot 10^{3} \\
3.078 \cdot 10^{-24}\left(\frac{\rho W}{L}\right)^{4} ; \frac{\rho W}{L} \geq 1767 \cdot 10^{3}\end{array}\right.$ \\
\hline Nusselt number & $N u_{g}=\left\{\begin{array}{l}4,36 ; \quad \operatorname{Re}_{g} \leq 2300 ; \\
\frac{(\xi / 8) \cdot\left(\operatorname{Re}_{g}-10^{3}\right) \cdot \operatorname{Pr}_{g}}{1+12.7 \sqrt{\xi / 8} \cdot\left(\operatorname{Pr}_{g}^{2 / 3}-1\right)} ; \operatorname{Re}_{g}>2300\end{array}\right.$ \\
\hline Friction coefficient & $\xi=\left(1.82 \cdot \lg \operatorname{Re}_{g}-1.64\right)^{-2}$ \\
\hline Auxiliary values & $\begin{array}{c}L=\sqrt{\frac{\sigma}{g \cdot\left(\rho^{\prime}-\rho^{\prime \prime}\right)}} ; \quad \operatorname{Re}_{g}=\frac{\rho w \cdot D}{\rho_{g} \cdot v_{g}} \cdot\left[x_{a c t}+\left(1-x_{a c t}\right) \frac{\rho_{g}}{\rho^{\prime}}\right] ; \quad \operatorname{Pr}_{g}=\frac{v_{g}}{a_{g}} \\
\text { where } \rho W \text { - mass flow rate; } v_{g} \text { - vapor kinematic viscosity coefficient; } a_{g} \text { - vapor thermal } \\
\text { diffusivity coefficient }\end{array}$ \\
\hline
\end{tabular}

\section{The Droplet Heat Transfer Determination in the Dispersed Flow Region}

The results received for the DFFB mode may be applied for the closure correlations improvement which is needed in two-fluid two-phase flow models.

Consider the total wall heat flux calculated with modified Hein-Köler model:

$$
Q_{w}^{\mathrm{H}-\mathrm{K}, \mathrm{m}}=\alpha_{w}^{\mathrm{H}-? \mathrm{~m}} \cdot A_{w} \cdot\left(T_{w}-T_{g}\right) .
$$

On the other hand:

$$
Q_{w}^{\mathrm{H}-\mathrm{K}, \mathrm{m}}=Q_{w g}+Q_{g d}+Q_{w d}+Q_{d, r a d},
$$

where $Q_{w g}$ - heat flux from the wall to the vapor; $Q_{g d}$ - heat flux from the vapor to the droplets; $Q_{w d}$ - heat flux from the wall to the droplets; $Q_{d, \text { rad }}$ - radiation heat flux to the droplets. 
The heat fluxes in the equation (5) are calculated as:

$$
Q_{w g}=\alpha_{w g} \cdot\left(A_{w}-A_{w d}\right) \cdot\left(T_{w}-T_{g}\right) \approx \alpha_{w g} \cdot A_{w} \cdot\left(T_{w}-T_{g}\right),
$$

where $A_{w d}<<A_{w}$ - the area of the droplets and wall contact; $\alpha_{w g}$ - the heat transfer coefficient from the wall to the vapor; it may be defined according to Miropolsky (1975):

$$
\alpha_{w g}=\frac{\lambda_{g}}{D} \cdot 0,028 \cdot \operatorname{Re}_{g}^{0,8} \cdot \operatorname{Pr}_{g}^{0,4} \cdot\left(\frac{\rho_{g w}}{\rho_{\mathrm{g}}}\right)^{1,15},
$$

$\rho_{g w}$ - the vapor density calculated at the wall temperature;

$$
Q_{g d}=\alpha_{g d} \cdot A_{d} \cdot\left(T_{g}-T_{s}\right),
$$

where $\alpha_{g d}$ - the heat transfer coefficient from the vapor to the droplets;

$$
Q_{w d}=\alpha_{w d} \cdot A_{w d} \cdot\left(T_{w}-T_{s}\right)
$$

where $\alpha_{w d}$ - the heat transfer coefficient from the wall to the droplets;

$$
Q_{d, r a d}=0 \text {, }
$$

if the wall temperature is less than $\sim 650^{\circ} \mathrm{C}$ and may be defined according to Sun, Gonzales-Santalo and Tien (1976) in the opposite case.

Table 3. Experimental regime parameters (Figure 3-4)

\begin{tabular}{lccccc}
\hline \multicolumn{1}{c}{ References } & $P, \mathrm{MPa}$ & $\rho W, \mathrm{\kappa} /\left(\mathrm{M}^{2} \mathrm{c}\right)$ & $q_{w}, \mathrm{MW} / \mathrm{m}^{2}$ & $x_{i n}$ & Regime designation \\
\hline (Nilsson, 1993) & \multirow{2}{*}{3} & 1503 & 0.77 & -0.024 & $\mathrm{a}$ \\
(Nilsson, 1993) & & 1010 & 0.67 & -0.026 & $\mathrm{~b}$ \\
(Bennett et al., 1967) & \multirow{2}{*}{6.9} & 1935 & 1.1 & -0.065 & $\mathrm{c}$ \\
& & 1003 & 0.79 & -0.08 & $\mathrm{~d}$ \\
\hline
\end{tabular}

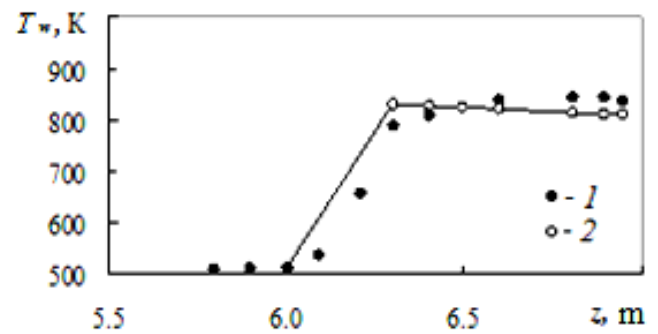

a)

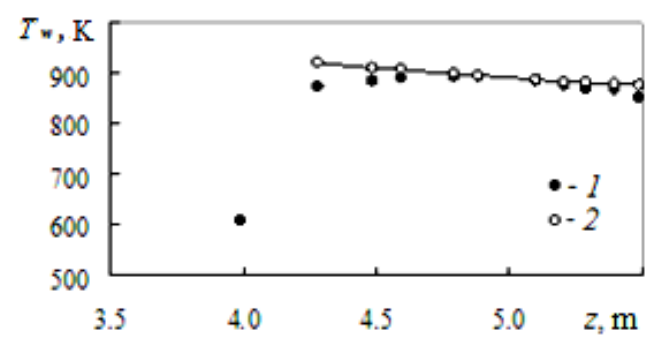

c)

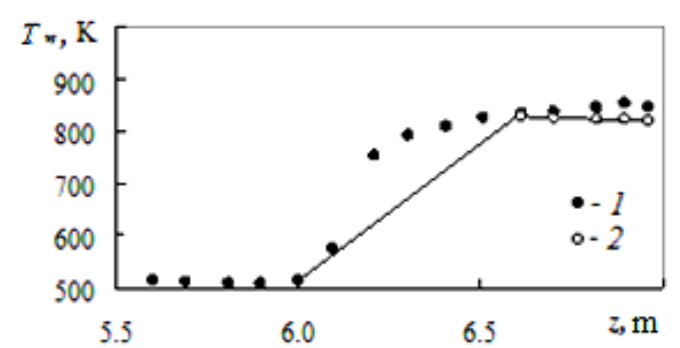

b)

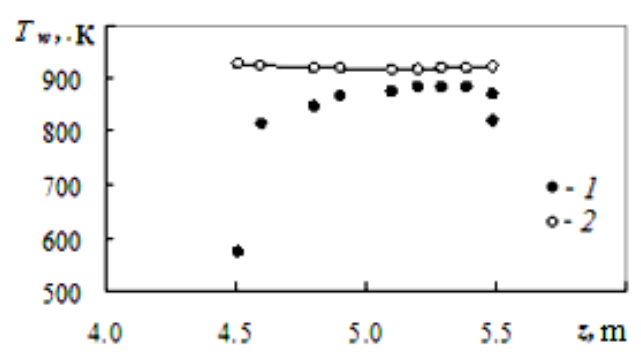

d)

Figure 3. The comparison of the experimental (1) and calculated in the present study (2) wall temperature values:

a) and b) - (Nilsson, 1993); c) and d) - (Bennett et al., 1967); (all regime parameters see in the Table 3) 
After substitution all formulas for the heat fluxes in the equation (5) the effective heat transfer to the droplets $\alpha_{d}^{e f f}$ may be defined as:

$$
\alpha_{d}^{e f f}=\alpha_{g d} \cdot \frac{A_{d}}{A_{\mathrm{w}}}+\alpha_{w d} \cdot \frac{A_{w d}}{A_{\mathrm{w}}} \cdot \frac{T_{w}-T_{S}}{T_{g}-T_{S}}+\frac{Q_{d, r a d}}{\left(T_{g}-T_{s}\right) \cdot A_{\mathrm{w}}}=\left(\alpha_{w}^{\mathrm{H}-\mathrm{K}, \mathrm{m}}-\alpha_{w g}\right) \cdot \frac{T_{w}-T_{S}}{T_{g}-T_{S}}
$$

where $\frac{A_{d}}{A_{w}}=0.9 \cdot \frac{D}{d} \cdot(1-\varphi)$ according to Ransom et al. (1985), $d$-droplet diameter.

This value is represented in Figure 4 as a function of the equilibrium relative enthalpy $x_{e q}$ in the post-dryout region.

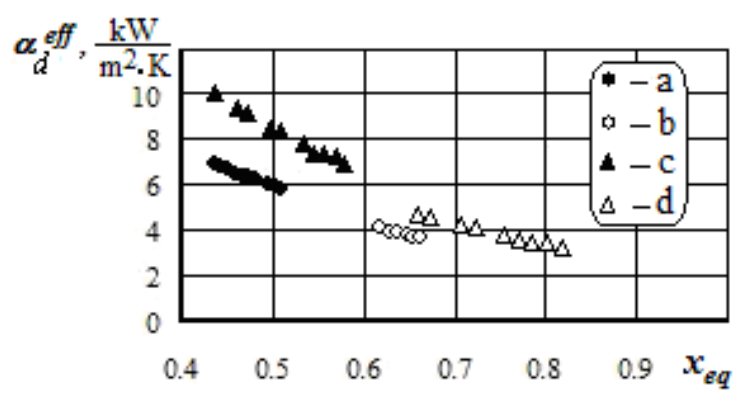

Figure 4. Effective heat transfer to the droplets $\alpha_{d}^{e f f}$ as a function of the equilibrium relative enthalpy $x_{e q}$ in the post-dryout region (the experimental regime parameters and the regime designation the same as in Figure 3 and Table 3)

It is seen that $\alpha_{d}^{e f f}$ tends to zero as $x_{e q}$ rises and void fraction tends to 1 . Thus the transition to the heat removal from the wall by the superheated vapor takes place.

Later the value of $\alpha_{d}^{e f f}-\frac{Q_{d, \text { rad }}}{\left(T_{w}-T_{s}\right) \cdot A_{w}}$ may be partitioned among the components of the relation (11), accounted for the droplet heat transfer with the vapor and the wall. Since today there are no reliable data observed experimentally for the droplets and wall interaction, values of the complex $\alpha_{w d} \cdot\left(A_{w d} / A_{w}\right)$ may be obtained if the proper recommendations for the droplet diameter in the dryout cross section and heat transfer between the droplets and the vapor will be assigned. Early decoding showed that the formula by Chen (2011) for the droplet diameter $d$

$$
\frac{d}{d_{c r}}=\left(\frac{1-x_{a c t}}{1-x_{a c t}^{c r}}\right)^{1 / 3} ; d_{c r}=798 \cdot \frac{\rho_{g}}{(\rho W) \cdot x_{a c t}^{c r}} \cdot\left(\frac{\sigma}{\rho^{\prime}}\right)^{0.5} \cdot\left(\frac{\mu_{g}}{(\rho W) \cdot x_{a c t}^{c r} \cdot D}\right)^{a} ;
$$

$a=0.63-0.1 \cdot p$ for $p<1.3 \mathrm{MPa} ; a=0.5$ for $p \geq 1.3 \mathrm{MPa}$ and the correlation by Whitaker (1972) for the droplets and the vapor heat transfer

$$
\begin{aligned}
& \alpha_{g d}=\frac{\lambda_{g}}{d_{d}} \cdot\left[2+\left(0.4 \cdot \operatorname{Re}_{d}^{1 / 2}+0.06 \cdot \operatorname{Re}_{d}^{2 / 3}\right) \cdot \operatorname{Pr}_{g}^{2 / 5} \cdot\left(\frac{\mu_{g}}{\mu_{g w}}\right)^{1 / 4}\right] \\
& \operatorname{Re}_{d}=\frac{\rho_{g} \cdot W_{R} \cdot d_{d}}{\mu_{g}} ; \quad 3.5 \leq \operatorname{Re}_{d} \leq 7.6 \cdot 10^{4} ; \quad \operatorname{Pr}=0.7-380
\end{aligned}
$$

conform to this aim.

With the help of this approach the separated values for the wall-droplets and vapor-droplets heat transfer coefficients may be obtained as it is necessary for the two-liquid two-phase models. 


\section{Conclusions}

The present study is devoted to the reliable wall temperature prediction in the post-crisis region of the heated channels when the inverted annular or the dispersed flow regime occurs. The corrections to the rather simple engineering models for the wall temperature calculation are proposed.

The introduction of the temperature factor $\gamma_{I A F B}=t_{w} / t_{s}$ in the original Hammouda's model (Hammouda et al., 1997) (inverted annular flow regime) with new approximations for the influence coefficient $\theta$ in the range of the Reynolds numbers $R e_{g}$ from 0 to $3 \times 10^{5}$ and for the vapor Nusselt number, which were obtained in this work, guarantee a better agreement of the calculated wall temperature values with experimental data.

A modified version of Hein-Köhler's model for heat transfer in the dispersed flow mode region ensures the better coincidence of the calculated temperature curve in the post-crisis region with experimental data than original one due to the use of correction in calculating nonequilibrium factor of two-phase flow.

The wall temperature calculations for the post-crisis flow regimes are represented. The data of Hammouda, Lapperiere, Miropolsky, Bennett and some other investigators were processed. The obtained average error and deviation for IAFB are less than those which take place when special best estimate computer code KORSAR is used. The model by Hein and Köhler enables only the effective heat transfer coefficient $\alpha_{w}^{\mathrm{H}-\mathrm{K}, \mathrm{m}}$ from the wall to the dispersed flow to be determined (without dividing in parts: to the vapor and to the liquid droplets). Therefore this model offered to be used for the heat transfer coefficient between the droplets and the wall determination.

Specified results may be applied for the closure correlations improvement which is needed in two-fluid two-phase flow models. Also the conclusion is made that the correct choice of the integration step and the method of the critical quality determination produce effect on the adequate wall temperature prediction.

\section{References}

Agafonova, N. D., \& Paramonova, I. L. (2013). Heat Transfer in Inverted Annular Mode of Steam-Water Flow. Thermal Engineering, 60(3), 176-181. http://dx.doi.org/10.1134/s0040601513030014

Bennett, A. W., Hewitt, G. F., Kearsey, H. A., \& Keeys, R. K. F. (1967). Heat transfer to steam-water mixtures flowing in uniformly heated tubes in which the critical heat flux has been exceeded. United Kingdom Atomic Energy Authority, AERE-R5373. http://dx.doi.org/10.1243/pime_conf_1967_182_237_02

Chen, Y. (2011). Heat Transfer in Film Boiling of Flowing Water, in: Heat transfer theoretical analysis, experimental investigations and industrial systems, edited Aziz Belmiloudi, InTech, 235-260. http://www.intechopen.com/books/heat-transfer-theoretical-analysis-experimental-investigations-andindustrial-systems. http://dx.doi.org/10.5772/14474.

Hammouda, N., Groeneveld, D. C., \& Cheng, S. C. (1997). Two-fluid modeling of inverted annular film boiling. Int. J. Heat Mass Transfer, 40(11), 2655-2670. http://dx.doi.org/10.1016/s0017-9310(96)00278-5

Kays, W. M., \& Leunge, E. V. (1963). Heat transfer in annular passages - Hydrodynamically developed turbulent flow with arbitrarily prescribed heat flux. Int. J. Heat Mass Transfer, 6(7), 537-557. http://dx.doi.org/10.1016/0017-9310(63)90012-7

Köhler, W., \& Hein, D. (1986). Influence of the wetting state of a heated surface on heat transfer and pressure loss in an evaporator tube. IAR, NUREG/IA-0003.

Lapperiere, A., \& Groeneveld, D. C. (1984). A Study of Low Quality Film Boiling at High Pressures and Flows. AIChE Symp. Series 236(80), 440-445.

Meholic, J. M. (2011). The development of a non-equilibrium dispersed flow film boiling heat transfer modeling package (Ph. D. thesis, The Pennsylvania State University, USA). Retrieved from https://etda.libraries.psu.edu/paper/11651

Miropolsky, Z. L. (1975). The Superheated Vapor Heat Transfer with Supply and Removal of Heat. Teploenergetika, 3, 75-78 [in Russian].

Nakla, M. E., Groeneveld, D. C., \& Cheng, S. C. (2011). Experimental Study of Inverted Annular Film Boiling in a Vertical Tube Cooled by R-134a. Int. J. Multiphase Flow, 37(1), 67-75. http://dx.doi.org/10.1016/j.ijmultiphaseflow.2010.08.006

Nilsson, L. (1993). Assessment of RELAP5/MOD3 against twenty-five post-dryout experiments performed at the Royal Institute of Technology. NUREG/IA-0094. STUDS VIK/NS-90/93, Sweden. 
Obot, N. T., \& Ishii, M. (1988). Two-Phase Flow Regime Transition Criteria in Postdryout Region Based on Flow Visualization Experiments. Int.J. Heat Mass Transfer, 31(12), 2559-2570. http://dx.doi.org/10.1016/00179310(88)90182-2

Petukhov, B. S. (1967). Heat Transfer and Pressure Drop during Laminar Flow in Tubes. Moscow: Energiya [in Russian].

Ransom, V. H. (1995). RELAP5/MOD2, Code Manual, Volume 1: Code structure, systems models and solution methods, NUREG/CR-5535. http://dx.doi.org/10.2172/105079

Sun, K. H., Gonzales-Santalo, J. M., \& Tien, C. L. (1976). Calculations of Combined Radiation and Convection Heat Transfer in Rod Bundles under Emergency Cooling Conditions. Trans.ASME, J. of Heat Transfer, 98(3), 414-420. http://dx.doi.org/10.1115/1.3450569

VDI Heat Atlas. (2010). Springer-Verlag Berlin Heidelberg. P. 1585. http://dx.doi.org/10.1007/978-3-54077877-6

Whitaker, S. (1972). Forced Convection Heat Transfer Correlations for Flow in Pipes, Past Flat Plates, Single Cylinders, Single Spheres and for Flow in Packed Beds and Tube Bundles. AIChE Journal, 18(2), 361-371. http://dx.doi.org/10.1002/aic.690180219

\section{Copyrights}

Copyright for this article is retained by the author(s), with first publication rights granted to the journal.

This is an open-access article distributed under the terms and conditions of the Creative Commons Attribution license (http://creativecommons.org/licenses/by/3.0/). 